\title{
The safety and efficacy of the IPACK block in primary total knee arthroplasty: a retrospective chart review
}

\author{
Michelle Biehl, MSc • Lisa Wild, NP • Kyle Waldman, MD, FRCPC • \\ Farzana Haq, MSc $\cdot$ Ronald A. Easteal, PhD $\cdot$ Monakshi Sawhney, PhD
}

Received: 26 October 2019/Revised: 19 March 2020/Accepted: 24 March 2020/Published online: 6 April 2020

(c) Canadian Anesthesiologists' Society 2020

\section{To the Editor,}

The interspace between the popliteal artery and posterior capsule of the knee (IPACK) block is an analgesic method for treating posterior knee pain in patients undergoing total knee arthroplasty (TKA). ${ }^{1-3}$ Anesthesiologists administer the IPACK block in combination with a femoral nerve block (FNB) or adductor canal block (ACB) to provide postoperative analgesia to the entire knee. ${ }^{2,3}$ There is limited information regarding the safety and efficacy of the IPACK block in patients undergoing primary TKA.

A retrospective chart review was conducted at Humber River Hospital in Toronto, Ontario, Canada to examine postoperative pain, ambulation distance, and adverse events (postoperative falls and foot drop). Ethics review and approval was obtained from the Research Ethics Board at Humber River Hospital (15 May 2018) and the Health Sciences and Affiliated Teaching Hospitals Research Ethics Board at Queen's University (HSREB\# 6023388,

\section{Biehl, MSc $(\bowtie) \cdot$ R. A. Easteal, PhD}

Department of Biomedical and Molecular Sciences, Queen's

University, Kingston, ON, Canada

e-mail: michelle.biehl@medportal.ca

\section{Wild, NP}

Department of Surgery, Humber River Hospital, Toronto, ON, Canada

K. Waldman, MD, FRCPC

Department of Anesthesiology, Humber River Hospital, Toronto, ON, Canada

F. Haq, MSc

Canadian Institute for Health Information (CIHI), Toronto, ON, Canada

M. Sawhney, $\mathrm{PhD}$

School of Nursing, Queen's University, Kingston, ON, Canada
13 August 2018). The electronic charts (MEDITECH@; Medical Information Technology, Inc., MEDITECH Circle, Westwood, MA, USA) of 869 consecutive patients who underwent TKA between 1 June 2017 and 30 June 2018 were screened. Patients were included if they underwent primary TKA and had a spinal anesthetic and single-shot nerve block. Patients who met inclusion criteria $(n=607)$ were analyzed in one of four groups based on the nerve block they received: FNB, FNB+IPACK, ACB, or $\mathrm{ACB}+\mathrm{IPACK}$.

Nurse practitioners recorded pain at rest and with movement using the 11-point numeric rating scale $(0=$ no pain, $10=$ the worst imaginable pain $)^{4}$ on the day of surgery, postoperative days (POD) 1 and 2, or until patient discharge (if it preceded POD 2). Physiotherapists recorded the patients' ambulation distance on POD 1 and POD 2. Length of hospital stay was calculated in hours from time of hospital admission to time of discharge.

Statistical hypothesis testing was not performed because of the large variation in the number of patients in each study group and the corresponding lack of power to detect significant differences between groups. Descriptive statistics are reported in the Table.

The mean (standard deviation) age of patients was 69.0 (9.0) $\mathrm{yr}$, and the majority were female and were American Society of Anesthesiologists physical status III. Mean pain scores on POD 0 for patients who received the $\mathrm{ACB}+\mathrm{IPACK}$ or FNB+IPACK were lower than those for patients who did not receive the IPACK block. There were no differences in pain intensity or distance ambulated between groups on POD 1 and 2. Three patients who received the FNB fell postoperatively when ambulating, which aligns with the known disadvantage of the FNB in causing quadricep muscle weakness. ${ }^{1-3}$ Four patients who were administered the ACB $(n=2)$ or ACB $+\operatorname{IPACK}(n=$ 
Table Patient characteristics and outcomes

\begin{tabular}{|c|c|c|c|c|}
\hline & $\mathrm{ACB}$ & $\mathrm{ACB}+\mathrm{IPACK}$ & FNB & $\mathrm{FNB}+\mathrm{IPACK}$ \\
\hline Total population $(n=607)$ & $n=267$ & $n=166$ & $n=141$ & $n=33$ \\
\hline Age (yr) & $68.1(8.8)$ & $69.4(8.9)$ & $70.4(9.4)$ & $68.6(9.7)$ \\
\hline Height (m) & $1.6(0.1)$ & $1.6(0.1)$ & $1.6(0.1)$ & $1.6(0.1)$ \\
\hline Weight $(\mathrm{kg})$ & $86.6(20.4)$ & $80.8(18.6)$ & $85.9(20.5)$ & $85.3(22.4)$ \\
\hline BMI $\left(\mathrm{kg} \cdot \mathrm{m}^{-2}\right)$ & $33.2(7.5)$ & $31.3(6.4)$ & $32.8(7.3)$ & $32.1(6.7)$ \\
\hline Female sex, $n \%$ & $188(70.4)$ & $115(69.3)$ & $93(66.0)$ & $19(57.6)$ \\
\hline \multicolumn{5}{|l|}{ ASA physical status, $n \%$} \\
\hline II & $43(16.1)$ & $30(18.1)$ & $20(14.2)$ & $3(9.1)$ \\
\hline III & $173(64.8)$ & $113(68.1)$ & $100(70.9)$ & $24(72.7)$ \\
\hline IV & $51(19.1)$ & $23(13.9)$ & $20(14.2)$ & $6(18.2)$ \\
\hline Not recorded & $0(0)$ & $0(0)$ & $1(0.7)$ & $0(0)$ \\
\hline \multicolumn{5}{|l|}{ Pain at rest (NRS) } \\
\hline POD 0 & $1.4(2.3)(n=266)$ & $0.6(1.7)(n=166)$ & $1.2(2.1)(n=140)$ & $0.7(2.1)(n=32)$ \\
\hline POD 1 & $3.9(2.9)(n=263)$ & $3.5(2.6)(n=166)$ & $3.5(2.9)(n=138)$ & $3.4(3.4)(n=33)$ \\
\hline POD 2 & $2.7(2.6)(n=261)$ & $2.6(2.5)(n=160)$ & $2.6(2.5)(n=139)$ & $2.8(2.6)(n=32)$ \\
\hline \multicolumn{5}{|l|}{ Pain with movement (NRS) } \\
\hline POD 0 & $1.9(2.3)(n=59)$ & $1.1(1.7)(n=25)$ & $1.5(2.3)(n=15)$ & $0(0)(n=3)$ \\
\hline POD 1 & $5.8(2.7)(n=160)$ & $5.3(2.7)(n=101)$ & $4.7(3.0)(n=74)$ & $3.5(2.9)(n=15)$ \\
\hline POD 2 & $4.0(2.8)(n=159)$ & $3.7(2.6)(n=96)$ & $4.0(2.6)(n=71)$ & $3.3(2.5)(n=21)$ \\
\hline Distance ambulated (m) & $18.7(14.5)(n=266)$ & $18.6(10.8)(n=161)$ & $17.5(11.6)(n=140)$ & $19.2(11.4)(n=33)$ \\
\hline \multicolumn{5}{|l|}{ POD 1} \\
\hline Distance ambulated (m) & $31.7(22.5)(n=241)$ & $30.0(17.3)(n=154)$ & $31.2(19.4)(n=127)$ & $36.5(22.1)(n=27)$ \\
\hline \multicolumn{5}{|l|}{ POD 2} \\
\hline $\begin{array}{l}\text { Total opioid consumption in } \\
\text { morphine equivalents (mg) }\end{array}$ & $145.7(75.0)(n=267)$ & $144.4(74.0)(n=166)$ & $135.0(59.5)(n=141)$ & $152.4(107.6)(n=33)$ \\
\hline Length of hospital stay (hr) & $67.3(44.7)(n=267)$ & $65.5(55.1)(n=166)$ & $69.8(42.0)(n=141)$ & $70.1(68.4)(n=33)$ \\
\hline
\end{tabular}

All quantities are expressed as mean (standard deviation) or $n(\%)$ where indicated

ACB = adductor canal block; ASA = American Society of Anesthesiologists; FNB = femoral nerve block; IPACK = interspace between the popliteal artery and posterior capsule of the knee; NRS = numeric rating scale; POD = postoperative day

2) experienced foot drop. Postoperative foot drop results from motor blockade of the common peroneal nerve or from surgically-induced trauma, therefore delaying ambulation and onset of physiotherapy. ${ }^{1-3}$ Surgically induced trauma was the reported cause of foot drop in the ACB group: the diagnosis of neurapraxia was suggested by the attending surgeon in both patients' electronic charts. Foot drop in the ACB+IPACK group was resolved by POD 2 in both patients. This transient block may be explained by pooling of local anesthetic around the common peroneal nerve after spreading from the IPACK injection site. ${ }^{4,5}$

Addition of the IPACK block to the ACB or FNB contributed to marginally lower mean pain scores in patients on POD 0; however, the analgesic benefit of the IPACK block was diminished on POD 1 and 2. IPACK block safety concerns manifested in two incidences of foot drop in the ACB+IPACK group. Future studies should focus on determining the optimal injection site and volume of the IPACK block that results in posterior knee analgesia without motor block.

\section{Conflicts of interest None.}

Funding statement None.

Editorial responsibility This submission was handled by Dr. Hilary P. Grocott, Editor-in-Chief, Canadian Journal of Anesthesia.

\section{References}

1. Cullom C, Weed JT. Anesthetic and analgesic management for outpatient knee arthroplasty. Curr Pain Headache Rep 2017; 21: 23-8.

2. Kukreja P, Feinstein J, Kalagara HK, et al. A summary of the anatomy and current regional anesthesia practices for 
postoperative pain management in total knee arthroplasty. Cureus 2018; DOI: https://doi.org/10.7759/cureus.2755.

3. Thobhani S, Scalercio L, Elliott CE, et al. Novel peripheral techniques for total knee arthroplasty promote reduced hospital length of stay: an analysis of 106 patients. Ochsner J 2017; 17: 233-8.

4. Benzon HT, Raja SN, Fishman SM, Liu SS, Cohen SP. Essentials of Pain Medicine. 4th ed. Philadelphia: Elsevier Inc.; 2018.
5. Niesen AD, Harris DJ, Johnson CS, et al. Interspace between popliteal artery and posterior capsule of the knee (IPACK) injectate spread: a cadaver study. J Ultrasound Med 2018; 38: $741-5$.

Publisher's Note Springer Nature remains neutral with regard to jurisdictional claims in published maps and institutional affiliations. 